\title{
Dietary properties and anthropometric findings of children with functional constipation: a cross-sectional study
}

\author{
Yeliz Çağan Appak, M.D. ${ }^{a}$, Miray Karakoyun, M.D. ${ }^{a}$, Nutritionist Tugce Koru ${ }^{b}$ and \\ Ass. Prof. Maşallah Baran. ${ }^{c}$
}

\begin{abstract}
Introduction. Functional constipation (FC) is a common problem in childhood. This study intended to investigate the dietary properties and anthropometric findings of children with FC. Population and methods. Patients with FC were defined according to the Rome IV diagnostic criteria. The control group included children who were not diagnosed with FC or any other organic disease. The children who admitted to pediatric gastroenterology outpatient clinic between September 2017-March 2018 were included. Anthropometric measurements of weight, height, and body mass index were recorded. Body mass index z-scores were used to identify for overweight and obese children. Malnutrition was defined according to Waterlow criteria. The three-day nutritional diaries of both FC patients and control subjects were assessed and the daily average of calorie, fiber, carbohydrate, protein and fat intake were calculated by the same nutritionist.
\end{abstract}

Results. Fourty patients with FC and fourty healthy control were included. Twenty-four patients with FC were in the normal height and weightranges. There was nosignificantdifference in the average daily calorie, carbohydrate, fat and fiber intake between the FC and control groups. Although protein ratios (\%) in the diet were found to be significantly lower in children with FC, the amount of protein that taken daily was found to be within normal limits in both groups. Conclusion. Most children with FC were in the normal range for height and weight. There was no significant relationship between FC and carbohydrate, fat and fiber content in the diet, only low protein ratios were found in FC.

Key words: constipation, proteins, fats, dietary fiber, anthropometry.

http:/ / dx.doi.org/10.5546/aap.2019.eng.e224

To cite: Çağan Appak Y, Karakoyun M, Koru T, Baran M. Dietary properties and anthropometric findings of children with functional constipation: a cross-sectional study. Arch Argent Pediatr 2019; 117(3):e224-e231.

\section{INTRODUCTION}

Constipation is the main issue that patients present with in 3-5\% of pediatric clinics and in $25 \%$ of pediatric gastroenterology clinics. ${ }^{1,2}$ The prevalence ranges of functional constipation (FC) is reported from $3 \%$ to $29.6 \% .^{3,4}$ This wide range in reported prevalence may be due to the use of different criteria to determine the presence of FC and could also result from cultural influences. ${ }^{5}$ The pathophysiology of constipation in children is not completely understood. Multiple factors are probably involved in the development of constipation, including genetic factors, intestinal motility disorders, fecal retention behavior and dietary habits. ${ }^{6,7} \mathrm{~A}$ low dietary fiber intake has been considered a risk factor for the development of FC and an increase in fiber consumption is an important part of treatment of FC in some studies. ${ }^{8,9}$ However, there is still no clear evidence to support the routine use of fiber supplements or other nutritional recommendations in the diet of FC patients as part of treatment. ${ }^{9,10} \mathrm{~A}$ normal fiber and fluid intake and balanced diet are recommended for FC children in the last European Society for Pediatric Gastroenterology, Hepatology and Nutrition (ESPGHAN) guideline but additional nutritional recommendations are not provided. ${ }^{11}$ In the literature, studies have reported various results after evaluating energy and dietary fiber intake and nutritional properties and relationships between FC, anthropometric measurements and appetite. ${ }^{6,7,10,12-14}$ Thus, the objective of this study was to determine calorie intake, dietary properties 
(fiber, carbohydrate, protein, fat content), anthropometric findings in FC children and the relationship between FC and these findings.

\section{POPULATION AND METHODS}

Functional constipation patients and healthy controls without FC who admitted to pediatric gastroenterology outpatient clinic between September 2017- March 2018, were included. Functional constipation patients were defined according to the Rome IV diagnostic criteria (Minimum 1-maximum 16 year-old). ${ }^{11}$ Patients who had constipation due to organic causes were not included in the study. The control group included children who were not diagnosed with FC or any other organic disease. The healthy controls were within normal limits of weight and height according to age. The healthy controls were matched with FC patients by age and gender. Patients' clinical and demographic data were determined. The children's clothes were removed and the weight was measured with the child standing on an electronic scale; height was measured using an adjustable stadiometer with the same devices. Anthropometric measurements of weight, height and body mass index (BMI) were obtained. Established reference values for Turkish children were used to calculate z-scores for weight, height and BMI. ${ }^{15}$ Obese and overweight patients were diagnosed according to World Health Organization criteria. ${ }^{16}$ Patients with BMI $z$-scores between +1 and +2 were considered overweight; those with scores above +2 were considered obese. Malnutrition was defined according to Waterlow criteria. ${ }^{17}$

Patients and controls were given a form for a three-day nutritional diary (see Annex). A brief training was given to the family about how to write nutritional contents with amounts. The parents wrote the food that their children ate for three days with the contents and amounts.
The three-day nutritional diaries of FC patients and healthy controls were assessed by the same nutritionist. The daily average calorie, carbohydrate, protein, fat and fiber contents were calculated by the same nutritionist using the Nutrient Data Base (BeBiS) program (BeBiS software program; Bebispro for Windows, Stuttgart, Germany; Turkish Version). Only the parents who could write three-day nutritional diaries correctly were included. Breastfed children were not included in the study because of the difficulty of assessing the amount and content in the breast milk. The daily requirement of fiber for FC patients and controls was calculated to be to $0.5 \mathrm{~g} / \mathrm{kg} /$ day. ${ }^{18}$ Additionally, the amounts of protein, carbohydrate, fat and fiber that the patients ingested daily were compared to the normal amounts that should be consumed in the diet. ${ }^{19}$ To determine the sample size, a priori power analysis was performed with the GPower3.1 package program. When the type I error is 0.05 and the Type II error is 0.20 , the study is planned to include at least a total of 70 individuals. We found that at least 35 individuals per group should be included in the study when the sample allocation rate is $1: 1$. Written informed consent was obtained from parents and patients who participated in this study. This study was performed in accordance with the Declaration of Helsinki for Human Research. Ethics committee approval was received from the Ethical Committee of SBU Tepecik Training and Research Hospital (17.08.2017/19).

\section{Statistical analaysis}

Quantitative variables were expressed as the mean and standard deviation, while the categorical variables were expressed as numbers and percentages. The data conforming to a normal distribution was evaluated using the Student's t-test. A chi-squared test was used for

TABLE 1. Demographic and anthropometric findings of the patients with functional constipation and controls

\begin{tabular}{lccc}
\hline & FC $(\mathbf{n}=\mathbf{4 0})$ & Control $(\mathbf{n}=\mathbf{4 0})$ & $p$ \\
\hline Age (mean years \pm SD) & $7.93 \pm 4.46$ & $8.13 \pm 4.5$ & 0.84 \\
Gender & & & 1.0 \\
Girls (n, \%) & $21(52.5 \%)$ & $21(52.5 \%)$ & \\
Boys (n, \%) & $19(47.5 \%)$ & $19(47.5 \%)$ & 0.87 \\
Body mass index z-scores (mean \pm SD) & $-0.37 \pm 1.34$ & $0.04 \pm 0.77$ & 0.74 \\
Weight/age & $101.4 \pm 26.7$ & $103 \pm 11.8$ & 0.27 \\
Height/age & $99.9 \pm 4.5$ & $100.9 \pm 3.7$ & 0.86 \\
Weight/height & $99.7 \pm 18$ & $100.3 \pm 7.4$ & \\
\hline
\end{tabular}

$\mathrm{FC}=$ functional constipation; $\mathrm{SD}=$ standard deviation. 
the comparison of categorical variables. All of the statistical tests were performed with the Statistical Package for the Social Sciences version 18.0 (SPSS, Inc., Chicago, IL, USA). A $p$-value of less than 0.05 was considered to be statistically significant.

\section{RESULTS}

Eighty children (40 with FC patients and 40 healthy control subjects) were selected for study. Demographic and anthropometric findings of the patients and controls are shown in Table 1 . The average onset age of constipation was $4.45 \pm 4.2$ years. The average duration of constipation was measured to be $41.9 \pm 46.9$ months, and average stool frequency was detected at $2.7 \pm 1.4$ per week. Painful defecation $(87.5 \%)$, history of large diameter stool $(85 \%)$, abdominal pain $(77.5 \%)$ and abdominal distension $(65 \%)$ were the most common complaints among FC patients. A family history of constipation was found in $47.5 \%$ of FC patients.

Among the FC patients, three were obese and one was overweight. Loss of appetite was noted in $24(60 \%)$ of FC patients. Malnutrition was found in $12(30 \%)$ of these patients, acute malnutrition in 9 patients, chronic malnutrition in 1 patient, and acute on chronic malnutrition in 2 patients. Twenty-four $(60 \%)$ patients with FC were within the normal height and weight ranges according to their age.

There was no significant difference in the average daily calorie $(\mathrm{kcal})$, carbohydrate, protein, fat and fiber intake between the FC and control groups (Table 2). Protein ratios in the diet (\%) were found to be significantly lower for FC patients. $(p=0.016)($ Table 2). However, when the amount of protein that the patients ingested daily was

TABLE 2. Average daily calorie, carbohydrate, fat and fiber intake of functional constipation and control patients

\begin{tabular}{|c|c|c|c|}
\hline Average daily intake & $\begin{array}{l}\text { FC }(n=40) \\
\text { Mean } \pm \text { SD }\end{array}$ & $\begin{array}{c}\text { Control }(n=40) \\
\text { Mean } \pm \text { SD }\end{array}$ & $p^{*}$ \\
\hline Calorie (kcal / kg) & $59.29 \pm 28.69$ & $60.49 \pm 31.37$ & 0.85 \\
\hline Carbohydrate (g/kg) & $6.54 \pm 3.17$ & $6.52 \pm 3.65$ & 0.98 \\
\hline Carbohydrate (\% / day) & $45.72 \pm 7.40$ & $45.27 \pm 9.23$ & 0.81 \\
\hline Protein $(\mathrm{g} / \mathrm{kg})$ & $1.99 \pm 1.07$ & $2.17 \pm 1.11$ & 0.46 \\
\hline Protein (\% / day) & $13.62 \pm 2.22$ & $15.37 \pm 3.90$ & 0.016 \\
\hline Fat $(\mathrm{g} / \mathrm{kg})$ & $2.59 \pm 1.39$ & $2.50 \pm 1.34$ & 0.76 \\
\hline Fat (\% / day) & $40.27 \pm 6.63$ & $39.57 \pm 7.08$ & 0.65 \\
\hline Fiber $(\mathrm{g} / \mathrm{kg})$ & $0.51 \pm 0.22$ & $0.52 \pm 0.26$ & 0.94 \\
\hline
\end{tabular}

$\mathrm{FC}=$ functional constipation; $\mathrm{SD}=$ standard deviation. ${ }^{*} \mathrm{~T}$-test was applied.

TABLE 3. Assessment of protein, carbohydrate, fat and fiber ratios in normal daily food content of functional constipation and control patients compared to normal ranges

\begin{tabular}{lccc}
\hline Daily average dietary content ${ }^{19}$ & $\begin{array}{c}\text { FC (n= 40) } \\
\mathbf{n}(\%)\end{array}$ & $\begin{array}{c}\text { Control (n=40) } \\
\mathbf{n}(\%)\end{array}$ & $p^{* * *}$ \\
\hline $\begin{array}{l}\text { Protein* } \\
<10 \% \text { (low) }\end{array}$ & - & & $1(2.5)$ \\
$10-30 \%$ (normal) & $40(100)$ & $39(97.5)$ & 0.31 \\
$>30 \%$ (high) & - & - & \\
Carbohydrate & $17(42.5)$ & $17(42.5)$ & 0.60 \\
$<45 \%$ (low) & $23(57.5)$ & $22(55)$ & \\
$45-65 \%$ (normal) & - & $1(2.5)$ & 0.43 \\
$>65 \%$ (high) & & & \\
Fat* & - & - & \\
$<25 \%$ (low) & $8(20)$ & $11(27.5)$ & \\
$25-35 \%$ (normal) & $32(80)$ & $29(72.5)$ & \\
$>35 \%$ (high) & & & \\
Fiber** & $19(47.5)$ & $18(45)$ & \\
Insufficient & $7(17.5)$ & $14(35)$ & \\
Normal & $14(35)$ & & \\
High & & & \\
\hline
\end{tabular}

*Percentage of protein, carbohydrate and fat in average daily nutrient intake; ${ }^{* *}$ The amount of fiber that should be consumed in a normal diet was determined to be $0.5 \mathrm{~g} / \mathrm{kg} /$ day; ${ }^{* *} \mathrm{Chi}$-squared test was used; FC: functional constipation. 
compared to the amount of protein that should be ingested in a normal diet, it was observed that the protein ratio in the nutritional content of all patients was within the normal limits and there was no significant difference compared to the control group $(p=0.31)$ (Table 3). There was also no significant difference in the carbohydrate and fat ratios of the FC patients compared to the control group. When the amounts of fiber they received were evaluated according to the amount of fiber that should need to take, it was seen that there was no significant difference between FC patients and controls (Table 2). Fat content of the diets were high in the patient and control group.

\section{DISCUSSION}

In this study, we did not find a significant difference between the healthy controls and FC patients in their average daily calorie, carbohydrate, fat and fiber intake. We found that protein ratios in FC patients were significantly lower than the healthy controls, although protein ratios in nutritional content of all patients were within normal limits. Different results have been reported in studies in which fiber and nutritional content are assessed in FC etiology and treatment. One previous study reported that increased dietary fiber intake was significantly associated with four or more bowel movements per week. ${ }^{20}$ In another study that included children with FC and a control group, both groups were investigated using a three-day dietary record. This study showed that constipated children consumed less fiber, protein, lipid, carbohydrate and calorie on a daily basis. The authors of this study warned that the intake of dietary fiber below the minimum recommendation is a risk factor for children with FC. ${ }^{21}$ In another study, dietary data revealed that the daily intake of energy and carbohydrates, caloric adequacy and the quantity of food ingested were increased during FC treatment. ${ }^{7}$

The NASPGHAN / ESPGHAN guidelines state that evidence does not support the use of extra fiber above the recommended intake in the treatment of FC. ${ }^{11,22}$ However, at least in the Western world, many children do experience a low fiber intake, resulting in a recommendation to increase the fiber intake up to the normal recommended level. In our study, it was also determined that the proportion of fiber in the diet of about half of the FC patients and half of the control group was low. However, data have never suggested that constipation worsened with a high-fiber diet. Consequently, the advice to consume a high-fiber diet should be considered as not recommended, but this does not mean that it is wrong. ${ }^{11,22}$

The guidelines also mention that fluid intake above the recommended guidelines was not shown to be beneficial in the treatment of constipation. ${ }^{11,22}$ In our study, we did not evaluate the relationship between daily amount of fluid intake and FC. However, we did not find any significant relationship between FC and nutrition in terms of dietary content and fiber intake. The guidelines recommend that dietary modifications should only be used to ensure a balanced diet and so that a sufficient amount of fiber and fluids are consumed.11,22 One study revealed that only fat per $100 \mathrm{kcal}$ positively correlated with $\mathrm{FC}^{13}$. In one study that used mice as subjects, feeding mice a high-fat diet resulted in intestinal dysbiosis and delayed colonic motility. ${ }^{23}$ However, in human studies, a high fat diet was not associated with retardation of colonic transit, although it has been shown that obesity was related to FC in children. ${ }^{24,25}$ In our study, a highfat diet was observed in children with FC, but the control group was also found to have a highfat diet. Nevertheless, most children with FC were detected to have normal height and weight ranges in terms of age. Different results have been reported in studies in which FC, anthropometric values and appetite were evaluated. While some studies have shown association with overweight and obesity and high caloric intake, some studies have shown increased appetite and calorie intake after constipation therapy. ${ }^{14,26}$ In a study in which 2820 children were assessed, children who were obese or overweight were not any more prevalent than FC children with normal weight $(12.9 \%, \mathrm{P}=0.73) .{ }^{14}$ Other studies have reported that $23 \%$ of children with FC were determined to be obese and $21 \%$ of children with FC were considered to be morbidly obese, which is higher than in the normal population..$^{27,28}$ In a study evaluating anthropometric measurements during FC treatment, it was revealed that there was not any significant change in z-score for weight for height, weight for age or height for age. Nevertheless, a significant increase was detected in mid-arm circumference and triceps skinfold thickness. ${ }^{7}$ Additionally, the literature has shown that chronic constipation may be accompanied by anorexia or a reduction in appetite. ${ }^{7,29}$ Our study revealed that loss of appetite occurred in $60 \%$ of FC patients. 
This study has some limitations. The nutritional content of patients' diets was evaluated using the information provided by the patients' families and based on the threeday diet list. For this reason, it can be assumed that the sociocultural status of the parents can affect the results. Fluid uptake was not assessed because it is not desired that be separately written by the parents. Patients were assessed for their anthropometric measurements over the weight and length, and measurements such as mid-arm circumference and triceps skinfold thickness were not evaluated.

\section{CONCLUSION}

The relationship between FC and nutrition and its role in treatment is controversial in the literature. In our study, the relationship between FC and fat, carbohydrate, and fiber content in the diet was not determined. Only low protein ratios in the diet were found in children with FC. Anthropometric findings of most children with FC were found to be in the normal ranges.

\section{Acknowledgements}

We would like to thank Research Assistant Busra Emir (Katip Celebi University) for statistical evaluation.

\section{REFERENCES}

1. Morais MB, Maffei HV. Constipação intestinal. J Pediatr (Rio J). 2000; 76 (Suppl 2):S147-56.

2. Benninga MA, Voskuijl WP, Taminiau JA. Childhood constipation: is there new light in the tunnel? J Pediatr Gastroenterol Nutr. 2004; 39(5):448-64.

3. Tabbers MM, Boluyt N, Berger MY, Benninga MA. Clinical practice: diagnosis and treatment of functional constipation. Eur J Pediatr. 2011; 170(8):955-63.

4. Ip KS, Lee WT, Chan JS, Young BW. A community-based study of the prevalence of constipation in young children and the role of dietary fibre. Hong Kong Med J.2005; 11(6):4316.

5. Mugie SM, Benninga MA, Di Lorenzo C. Epidemiology of constipation in children and adults: a systematic review. Best Pract Res Clin Gastroenterol. 2011; 25(1):3-18.

6. Morais MB, Vítolo MR, Aguirre AN, Fagundes-Neto U. Measurement of low dietary fiber intake as a risk factor for chronic constipation in children. J Pediatr Gastroenterol Nutr. 1999; 29(2):132-5.

7. Speridião PG, Tahan S, Fagundes-Neto U, Morais MB. Dietary fiber, energy intake and nutritional status during the treatment of children with chronic constipation. Braz J Med Biol Res. 2003; 36(6):753-9.

8. RajindrajithS, Devanarayana NM. Constipation in children: novel insight into epidemiology, pathophysiology and management. J Neurogastroenterol Motil. 2011; 17(1):35-47.

9. Chao HC, Lai MW, Kong MS, ChenSY, et al. Cutoff volume of dietary fiber to ameliorate constipation in children. J Pediatr. 2008; 153(1):45-9.

10. de Mello PP, Eifer DA, de Mello ED. Use of fibers in childhood constipation treatment: systematic review with meta-analysis. J Pediatr (Rio J). 2018; 94(5):460-70.

11. Hyams JS, Di Lorenzo C, Saps M, Shulman RJ, et al. Functional Disorders: Children and Adolescents. Gastroenterology. 2016:S0016-5085(16)00181-5.

12. Maffei HV, Vicentini AP. Prospective evaluation of dietary treatment in childhood constipation: high dietary fiber and wheat bran intake are associated with constipation amelioration. J Pediatr Gastroenterol Nutr. 2011; 52(1):55-9.

13. Fujitani A, Sogo T, Inui A, Kawakubo K. Prevalence of Functional Constipation and Relationship with Dietary Habits in 3- to 8-Year-Old Children in Japan. Gastroenterol Res Pract. 2018; 2018:3108021.

14. Koppen IJ, Velasco-Benítez CA, Benninga MA, Di Lorenzo C, Saps M. Is There an Association between Functional Constipation and Excessive Bodyweight in Children? J Pediatr. 2016; 171:178-82.e1.

15. Neyzi O, Bundak R, Gökçay G, Günöz H, et al. Reference Values for Weight, Height, Head Circumference and Body Mass Index in Turkish Children.JClin Res Pediatr Endocrinol. 2015; 7(4):280-93.

16. WHO Multicentre Growth Reference Study Group. WHO Child Growth Standards based on length/height, weight and age. Acta Paediatr Suppl. 2006; 450:76-85.

17. Waterlow JC. Classification and definition of protein-calorie malnutrition. Br Med J. 1972; 3(5826):566-9.

18. WilliamsCL, BollellaM, WynderEL. Anew recommendation for dietary fiber in childhood. Pediatrics. 1995; 96(5 Pt2):9858.

19. Gidding SS, Dennison BA, Birch LL, Daniels SR, et al. Dietary recommendations for children and adolescents: a guide for practitioners. Pediatrics. 2006; 117(2):544-59.

20. Asakura K, Masayasu S, Sasaki S. Dietary intake, physical activity, and time management are associated with constipation in preschool children in Japan. Asia Pac J Clin Nutr. 2017; 26(1):118-29.

21. Gomes RC, Maranhão HS, Pedrosa Lde F, Morais MB. Consumo de fibra alimentar e de macronutrientes por crianças com constipação crônica funcional. Arq Gastroenterol. 2003; 40(3):181-7.

22. Tabbers MM, DiLorenzo C, Berger MY, Faure C, et al. Evaluation and treatment of functional constipation in infants and children: evidence-based recommendations from ESPGHAN and NASPGHAN. J Pediatr Gastroenterol Nutr. 2014; 58(2):258-74.

23. Anitha M, Reichardt F, Tabatabavakili S, Nezami BG, et al. Intestinal dysbiosis contributes to the delayed gastrointestinal transit in high-fat diet fed mice. Cell Mol Gastroenterol Hepatol. 2016; 2(3):328-39.

24. Cummings JH, Wiggins HS, Jenkins DJ, Houston $\mathrm{H}$, et al. Influence of diets high and low in animal fat on bowel habit, gastrointestinal transit time, fecal microflora, bile acid, and fat excretion. J Clin Invest. 1978; 61(4):953-63.

25. Phatak UP, Pashankar DS. Prevalence of functional gastrointestinal disorders in obese and overweight children. Int J Obes (Lond). 2014; 38(10):1324-7.

26. Koppen IJ, Kuizenga-Wessel S, Saps M, Di Lorenzo C, et al. Functional Defecation Disorders and Excessive Body Weight: A Systematic Review. Pediatrics. 2016; 138:e20161417.

27. vd Baan-Slootweg OH, Liem O, Bekkali N, van Aalderen WM, etal. Constipation and colonic transit times in children with morbid obesity. J Pediatr Gastroenterol Nutr. 2011; 52(49:442-5.

28. Fishman L, Lenders C, Fortunato C, Noonan C, Nurko S. Increased prevalence of constipation and fecal soiling in a population of obese children. J Pediatr. 2004; 145(2):253-4.

29. Keuzenkamp-Jansen CW, Fijnvandraat CJ, Kneepkens CM, Douwes AC. Diagnostic dilemmas and results of treatment for chronic constipation. Arch Dis Child. 1996; 75(1):36-41. 
ANNEX

THREE-DAY NUTRITIONAL DIARY (FOOD CONSUMPTION FORM)

\section{NAME-SURNAME:}

AGE:

LENGHT:

WEIGHT:

IMPORTANT TOPICS:

1. When filling out the food consumption form, write down the days and meals separately.

2. Write the nutrients correctly and exactly.

For example:

The type of soup (tarhana soup, noodle soup.. etc.)

Meat meals should write like as Izmir meatballs, chicken grilled

Vegetables meals should write like as peas or leeks..etc

3.Write down the main ingredients in the food.

For example:

Sandwich $=1$ matchbox of salt-free cheese + half tomato +2 thin slices of white saltfree bread

Pepper stuffing 2 pieces $=$ ground beef and rice

Pastry = Quarter filo pastry, 4 tablespoons of curd and 1 tablespoon of parsley

4. It is important to write the correct amount of food.

Quantity, tablespoon, teaspoon, scoop, 1 tea cup, 1 cup, large size, half, thin slices, etc. Please specify the size.

5. Please write the type of bread you consume.

For example:

White, salty bread; white, salt-free bread; wholemeal bread, etc.

6. Please indicate whether your meals are salted or salt-free.

7. Write the amount of sugar used in tea. 
e230 / Arch Argent Pediatr 2019;117(3):e224-e231 / Original article

\begin{tabular}{|c|c|c|}
\hline 1.DAY & NUTRIENT & QUANTITY-SIZE \\
\hline \multicolumn{3}{|c|}{ BREAKFAST } \\
\hline \multicolumn{3}{|l|}{ SNACK } \\
\hline \multicolumn{3}{|c|}{ MIDDAY } \\
\hline \multicolumn{3}{|l|}{ SNACK } \\
\hline \multicolumn{3}{|l|}{ DINNER } \\
\hline \multicolumn{3}{|l|}{ SNACK } \\
\hline 2.DAY & NUTRIENT & QUANTITY-SIZE \\
\hline \multicolumn{3}{|c|}{ BREAKFAST } \\
\hline \multicolumn{3}{|l|}{ SNACK } \\
\hline \multicolumn{3}{|c|}{ MIDDAY } \\
\hline \multicolumn{3}{|l|}{ SNACK } \\
\hline \multicolumn{3}{|l|}{ DINNER } \\
\hline SNACK & & \\
\hline
\end{tabular}


Dietary properties and anthropometric findings of children with functional constipation: a cross-sectional study / e231

\begin{tabular}{|l|l|l}
\hline 3.DAY & NUTRIENT & QUANTITY-SIZE \\
\hline BREAKFAST & & \\
\hline SNACK & & \\
\hline MIDDAY & & \\
\hline SNACK & & \\
\hline DINNER & & \\
& & \\
\hline SNACK & & \\
\hline
\end{tabular}

